\title{
Comparing strategies for United States veterans' mortality
} ascertainment

\author{
Karl A Lorenz*1,2,3, Steven M Asch ${ }^{1,2,3}$, Elizabeth M Yano ${ }^{1,4}$, \\ Mingming Wang ${ }^{1}$ and Lisa V Rubenstein ${ }^{1,2,3}$
}

Address: ${ }^{1}$ VA Greater Los Angeles Healthcare System, Los Angeles CA, USA, ${ }^{2}$ Geffen School of Medicine at UCLA, Los Angeles CA, USA, ${ }^{3}$ RAND, Santa Monica CA, USA and ${ }^{4}$ Department of Health Services, UCLA School of Public Health, Los Angeles CA, USA

Email: Karl A Lorenz* - karl.lorenz@med.va.gov; Steven M Asch - sasch@rand.org; Elizabeth M Yano - elizabeth.yano@med.va.gov; Mingming Wang - mingming.wang@med.va.gov; Lisa V Rubenstein - lisa.rubenstein@med.va.gov

* Corresponding author

Published: 24 February 2005

Population Health Metrics 2005, 3:2 doi:10.I I86/1478-7954-3-2

This article is available from: http://www.pophealthmetrics.com/content/3/l/2

(C) 2005 Lorenz et al; licensee BioMed Central Ltd.

This is an Open Access article distributed under the terms of the Creative Commons Attribution License (http://creativecommons.org/licenses/by/2.0), which permits unrestricted use, distribution, and reproduction in any medium, provided the original work is properly cited.
Received: 18 August 2004

Accepted: 24 February 2005

\begin{abstract}
Background: We aimed to determine optimal strategies for complete mortality ascertainment comparing death certificates and United States (US) Veterans Administration (VA) records.

Methods: We constructed a cohort of California veterans who died in fiscal year (FY) 2000 and used VA services the year before death. We determined decedent status using California death certificates linked to VA utilization data and the VA Beneficiary Identification and Records Locator System (BIRLS) death file. We compared the characteristics of decedents who would not have been identified by either single source (e.g., VA BIRLS alone or California death certificates alone) with the rest of the cohort.
\end{abstract}

Results: A total of 8,813 veteran decedents were identified from both VA decedent files and death certificates. Of all decedents, 5,698 / 8,813 (65\%) veterans were identified in both source files, but $2,426 / 8,813$ (28\%) decedents were not identified in VA BIRLS, and 689 / 8,8I3 (8\%) were not identified in death certificates. Compared to the rest of the cohort, decedents whose mortality status was ascertained through either single source differed by race / ethnicity, marital status, and California residence. Clinically, veterans identified from either single source had less comorbidity and were less likely to have been users of VA inpatient or long term care, but equally or more likely to have been users of VA outpatient services.

Conclusion: As single sources, VA decedent files and death certificates each provided an incomplete record, and death ascertainment was improved by using both source files. Potential bias may vary depending on analytic interest.

\section{Introduction}

Clinicians, healthcare administrators, researchers, regulators and policymakers are concerned with optimizing mortality ascertainment using administrative data. In addition to its clinical importance, mortality informs pro- gram planning, quality assessment and improvement, and public reporting [1-8]. Veterans are an important, vulnerable population in which mortality has been examined as a function of race / ethnicity, service characteristics, access, and quality of care. Valid, complete reporting is 
critical to the success of such endeavors, and limitations in using death certificates have been acknowledged $[9,10]$, although VA mortality data is generally regarded as accurate [11-15]. To understand the limitations of single source ascertainment, we described decedents who would not have been identified by a strategy using either VA decedent files alone or death certificates alone. We compared cases that would have been missed using either single source with the rest of the cohort based on their demographic and clinical attributes and the settings in which they received care.

\section{Methods}

In order to evaluate the implications for improving veterans' end-of-life care, we constructed a population-based decedent cohort [16]. For such purposes, it is particularly important to understand whether death was recorded elsewhere for veterans who were under VA care since the VA system may be responsible for much of their end-oflife care even if they do not die while receiving health care in a VA facility.

\section{Data Sources}

The VA Beneficiary Identification and Records Locator System (BIRLS) contains records of all beneficiaries including veterans whose survivors applied for burial benefits. It includes records of discharged military veterans post-1973 and recipients of Medals of Honor and VA education benefits. After submission to the Veterans Benefits Administration (VBA), deaths are recorded in the BIRLS Death File. A submission to the VBA is typically triggered by a family claim for death benefits (e.g. burial assistance, pension) [17-19]. The VA maintains a National Patient Care Database (NPCD) that contains a record of Social Security Number (SSN) linked VA and contracted health services provided to all veterans [17-19]. Death certificates are required for burial in California and are available for public use [20].

We first identified 345,380 decedent veterans who died during FY2000 (30 September 1999 - 1 October 2000) from the BIRLS Death File. We used SSNs to link cases to VA NPCD outpatient, inpatient, or long term care records restricted to recipients of any VA services in California within 12 months of death. We extracted records including any inpatient or long term care admission, or outpatient encounters. Veterans who entered the cohort on the basis of using outpatient services were required to have at least one clinical encounter (e.g., other than laboratory, radiology, or administrative).

In addition, we used California death certificates as second source to identify decedent veterans by linking SSNs from death certificates directly to VA utilization files. California death certificates contained 462,561 records for calendar years 1999 and 2000, and we primarily matched decedents identified through death certificates to BIRLS by SSN. We manually inspected matches on SSN only and we also examined matches on criteria other than SSN (e.g. last name, first name, date of birth, date of death). Additional cases we accepted after manual inspection involved transpositions of one and rarely more than one SSN digit but agreement in other fields. Thus, the cohort included recipients of VA clinical services verified as deceased based on either BIRLS or death certificates, and all cases were linked to VA utilization files by SSN.

In the final decedent cohort, we excluded cases of non-veterans receiving care at VA facilities by examining indicators of veteran status associated with visits. The VA assigns specific codes to non-veterans rendered care for various reasons (e.g., emergency or charitable care). We also considered the possibility of erroneous decedent status by looking for evidence of healthcare utilization during the 12 months after death. We excluded cases with evidence of utilization more than one month after the date of death.

\section{Variables and Analysis}

We used VA encounters and ICD-9-CM codes to demographically (e.g., age, gender, marital status, state of residence, and race / ethnicity) and clinically characterize decedents [21-26]. We identified veterans with any visit or admission for congestive heart failure (CHF), ICD-9-CM 398.91，402.x1，404.x1，404.x3 428.x excluding procedures, chronic obstructive lung disease (COPD), ICD-9CM 491-492.x, 494.x, 496, end-stage liver disease (ESLD), ICD-9-CM 571.2-571.9,572.2-572.8, dementia, ICD-9-CM 046.1, 290.0-290.43, 331.0-331.7, 333.4, 438.0, and malignant neoplasia, ICD-9-CM 140.0-208.9 [25]. To identify end-stage renal disease (ESRD), we used procedure and clinical stop codes that identify the type of care received (e.g., dialysis) [26]. We developed a complexity index of co-morbidity based on a simple count of advanced illnesses.

To understand the limitations of single source mortality ascertainment, we described decedents who would not have been identified by a strategy using either death certificates alone or VA decedent files alone. We compared these cases with the rest of the cohort based on their demographic and clinical attributes and the settings in which they received care. Based on distributions, we used Wilcoxon tests for continuous and chi-square tests for categorical variables.

\section{Results}

From 345,380 deaths during the period 30 September 1999 to 1 October 2000 identified in BIRLS, we distinguished 6,071 decedents who were users of VA inpatient, 


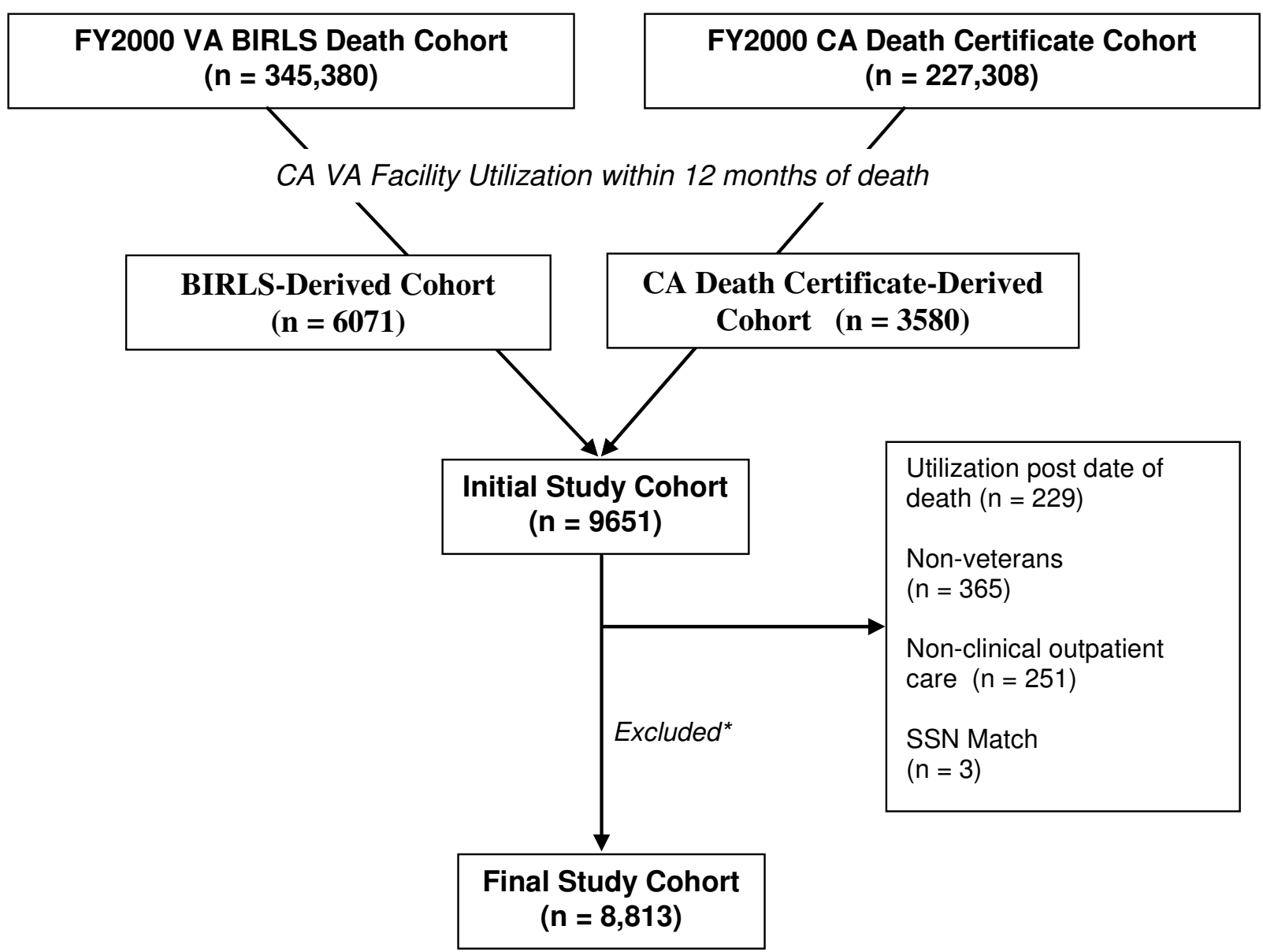

*10 cases were excluded for more than 1 reason.

Figure I

Cohort Development

outpatient, or long term care services in California. California death certificates included 227,308 deaths during the same period, including 3,580 additional users of VA inpatient, outpatient, or long term care services in California. Using SSN and other identifiers to match decedent cases to VA utilization data, we excluded non-veterans (n = 365), users of only non-clinical care such as laboratory tests $(\mathrm{n}=251)$, those possibly alive based on subsequent VA encounter data $(\mathrm{n}=229)$, and 3 cases for other reasons. Of the final cohort of 8,813 veteran decedents, $5,698(65 \%)$ cases were identified in both source files, while $689(8 \%)$ were only identified in VA decedent files, and 2,426 (28\%) additional cases were only identified through death certificates (Figure 1).

We examined potential biases associated with veteran decedents missed by either single source of mortality ascertainment (e.g., VA BIRLS or California death certificates). Ninety-nine percent of decedents missed by using VA data alone were California residents (vs. 92\% of the remainder cohort, $\mathrm{p}<0.001$ ); whereas, $62 \%$ of those missed by using death certificates alone were out-of-state residents (vs. $1 \%$ of the remainder cohort, $\mathrm{p}<0.001$ ). Relatively fewer veterans of white or black ethnicity and 
Table I: Potential Bias Associated with Alternative Strategies For Veterans' Mortality Ascertainment *

\begin{tabular}{|c|c|c|c|c|c|c|}
\hline & \multicolumn{3}{|c|}{ BIRLS Only Strategy } & \multicolumn{3}{|c|}{ Death Certificate Only Strategy } \\
\hline & $\begin{array}{r}\text { Cases identified by } \\
\text { BIRLS }\end{array}$ & $\begin{array}{r}\text { Additional cases } \\
\text { identified by death } \\
\text { certificates }\end{array}$ & P-value & $\begin{array}{r}\text { Cases identified by } \\
\text { death certificates }\end{array}$ & $\begin{array}{r}\text { Additional cases } \\
\text { identified by BIRLS }\end{array}$ & P-value \\
\hline Number of cases & 6,387 & 2,426 & & 8,124 & 689 & \\
\hline Age (years) & 70.86 & 71.15 & 0.8253 & 70.95 & 70.79 & 0.6891 \\
\hline \multicolumn{7}{|l|}{ Gender } \\
\hline Male & 98 & 97 & 0.2733 & 98 & 98 & 0.8662 \\
\hline \multicolumn{7}{|l|}{ Race / Ethnicity } \\
\hline White & 57 & 54 & & 58 & 31 & $<0.001$ \\
\hline Black & 12 & 8 & & 11 & 6 & \\
\hline Hispanic & 5 & 5 & & 5 & 1 & \\
\hline Other & 2 & 2 & & 2 & 1 & \\
\hline Missing & 24 & 31 & $<0.001$ & 23 & 61 & \\
\hline \multicolumn{7}{|l|}{ Marital Status } \\
\hline Married & 46 & 49 & & 47 & 45 & 0.0028 \\
\hline Single & 16 & 13 & & 15 & 16 & \\
\hline Divorced & 23 & 24 & & 23 & 23 & \\
\hline Widowed & 11 & 12 & & 11 & 11 & \\
\hline Missing & 4 & 2 & 0.0002 & 3 & 6 & \\
\hline \multicolumn{7}{|l|}{ State of Residence } \\
\hline California & 92 & 99 & & 99 & 38 & \\
\hline Non-California & 8 & 1 & $<0.001$ & 1 & 62 & $<0.001$ \\
\hline \multicolumn{7}{|l|}{ Diagnosis } \\
\hline Cancer & 35 & 32 & 0.0426 & 35 & 17 & $<0.001$ \\
\hline $\mathrm{CHF}$ & 22 & 19 & 0.0175 & 22 & 7 & $<0.001$ \\
\hline COPD & 28 & 24 & 0.0002 & 28 & 11 & $<0.001$ \\
\hline ESLD & 6 & 4 & 0.0327 & 6 & 3 & 0.0010 \\
\hline ESRD & 3 & 1 & $<0.0001$ & 3 & 0 & 0.001 \\
\hline Dementia & 11 & 11 & 0.9656 & 11 & 3 & $<0.001$ \\
\hline HIV & 1 & 1 & 0.1586 & 1 & 0 & 0.0621 \\
\hline \multicolumn{7}{|l|}{ Complexity Index } \\
\hline 0 & 35 & 37 & & 32 & 69 & \\
\hline I & 35 & 39 & & 38 & 22 & \\
\hline 2 & 22 & 18 & & 22 & 6 & \\
\hline 3 & 7 & 5 & & 7 & 2 & \\
\hline 4 & 1 & $\mathrm{I}$ & $<0.0001$ & 1 & 0 & $<0.001$ \\
\hline \multicolumn{7}{|l|}{ Site of Utilization } \\
\hline \multicolumn{7}{|l|}{ Any inpatient } \\
\hline Any long term & 45 & 29 & $<0.0001$ & 42 & 21 & $<0.001$ \\
\hline care & 20 & 12 & $<0.0001$ & 19 & 7 & $<0.001$ \\
\hline Any outpatient & 95 & 96 & 0.0225 & 95 & 96 & 0.1218 \\
\hline
\end{tabular}

*Findings are expressed as proportions unless otherwise identified. P-values reflect Wilcoxon two-sided probabilities for continuous variables and chi-square for categorical variables. Categorical tests reflect tests for differences including missing. 
relatively more veterans of missing ethnicity were represented among decedents missed by either single source strategy. The proportion of married or previously married veterans was higher and single or missing marital status lower among those decedents missed using only BIRLS, and relative proportions were reversed for a strategy using only death certificates.

Decedents missed by either single source approach were less likely to have been diagnosed with an advanced chronic illness than the identified cohort. Veteran decedents missed by using only BIRLS were less likely to be diagnosed with any condition except HIV and dementia, and those missed by using death certificates alone were less likely to be diagnosed with any condition except HIV. With a BIRLS only approach, $37 \%$ of missing cases vs. $35 \%$ of the remainder cohort $(\mathrm{p}<0.001)$ had no diagnosed chronic illness (death certificate only approach; $69 \%$ vs. $32 \%, \mathrm{p}<0.001)$. Veteran decedents missed by either single source approach were equally or more likely to have been users of the outpatient setting, but missed cases were less likely to have been users of inpatient healthcare settings (Table 1).

\section{Discussion}

Veterans' mortality ascertainment was significantly improved by using both VA and death certificates as source files. Our findings indicate that either single source approach for mortality ascertainment may misrepresent veteran mortality based on comparisons of race / ethnicity, marital status, severity of illness, and settings of care. Diagnoses associated with serious medical co-morbidity and the likelihood of receiving any inpatient services (e.g. hospital or long term care) were both significantly lower among veterans missed by either single source approach.

Our findings are consistent with Washington State where the deaths of $25 \%$ of 533 veterans who only used outpatient services were only identified with death certificates, and 5\% were only identified in BIRLS. [9] Using BIRLS only for mortality determination, it is unclear why generally healthier, primarily outpatient users are less likely to be noted. Death notification is typically triggered by benefit claims (e.g., burial assistance, pension and related benefits). Affluent veterans whose families might be less likely to file benefit claims were drawn to the VA recently [27]. However, poverty or low social support might also make it harder to file claims. On the other hand, a death certificate only approach to ascertainment misses relatively fewer non-resident veterans. Such veterans may be homeless or mobile, retired veterans, and they may seek care transiently in California, or their deaths may be recorded elsewhere.
One limitation of our study is that we did not identify cases that were only decedents by virtue of VA utilization files alone rather than BIRLS, although Dominitz, et. al., identified only $2.7 \%$ of deaths this way [11]. We did not compare VA files or death certificates to the National Death Index (NDI), as have previous studies that have used the NDI as a gold standard. The NDI is a central data repository of state vital statistics that is often used as a gold standard in US mortality studies [28]. We report findings for only one state, but given similar findings in Washington State, it would be helpful to determine if this is a national issue or there are particular state issues related to BIRLS death file agreement, or concerns related to veteran morality ascertainment with California death certificates.

\section{Conclusion}

Researchers, managers, and policy makers should understand the limitations of sources of mortality ascertainment. The relationship of missing data to bias is related somewhat to how "missingness" is distributed by the outcome of interest. Our findings suggest these concerns may be relatively more important for studies involving veterans and racial-ethnic disparities, co-morbidity, certain disease comparisons, or settings of care. Additional study is needed to compare BIRLS, death certificates, and the NDI for mortality ascertainment in veterans. If our findings are confirmed, the VA may need to consider improving its system for mortality ascertainment through routine linkages to national mortality data. Studies of end-of-life care using decedent cohorts need to pay particular attention to the incompleteness of VA data as the sole source of mortality information.

\section{List of Abbreviations Used}

VA, Veterans Administration; FY, fiscal year; BIRLS, Beneficiary Identification and Records Locator System; NPCD, National Patient Care Database; SSN, Social Security Number; CHF, congestive heart failure; COPD, chronic obstructive lung disease; ESLD, end-stage liver disease; ESRD, end-stage renal disease.

\section{Competing interests}

The author(s) declare that they have no competing interests.

\section{Authors' contributions}

$\mathrm{KL}$ originated and oversaw all aspects of the conception, design, analysis, and publication of the study. SA, LR, and EY contributed to conception, design, and analysis. MW contributed to analysis and is responsible for programming. All authors reviewed and approved of the manuscript. 


\section{Acknowledgements}

Dr. Lorenz is a recipient of a VA HSR\&D Career Development Award These analyses were also supported by a Locally Initiated Project award (LIP \# 200I-00I) from the VA Greater Los Angeles HSR\&D Center of Excellence. The views expressed in this article are those of the authors and do not necessarily represent the views of the Department of Veterans Affairs.

\section{References}

I. Ashton CM, Souchek J, Petersen NJ, Menke TJ, Collins TC, Kizer KW, Wright SM, Wray NP: Hospital use and survival among Veterans Affairs beneficiaries. N Engl J Med 2003, 349(I 7): I637-46.

2. Freeman VL, Durazo-Arvizu R, Arozullah AM, Keys LC: Determinants of mortality following a diagnosis of prostate cancer in Veterans Affairs and private sector health care systems. Am J Public Health 2003, 93( I 0): I 706-I2.

3. Young BA, Maynard C, Boyko EJ: Racial differences in diabetic nephropathy, cardiovascular disease, and mortality in a national population of veterans. Diabetes Care 2003, 26(8):2392-9.

4. Indridason OS, Coffman CJ, Oddone EZ: Is specialty care associated with improved survival of patients with congestive heart failure? Am Heart J 2003, I 45(2):300-9.

5. Johnston JA, Wagner DP, Timmons S, Welsh D, Tsevat J, Render ML: Impact of different measures of comorbid disease on predicted mortality of intensive care unit patients. Med Care 2002, 40(1 0):929-40.

6. Loria CM, Sempos CT, Vuong C: Plan and operation of the NHANES II Mortality Study, 1992. Vital Health Stat I 1999: I- 16.

7. Lanska DJ, Dementia mortality in the United States: Results of the I 986 National Mortality Followback Survey. Neurology 1998, 50(2):362-7.

8. Ghali WA, Rothwell DM, Quan H, Brant R, Tu JV: A Canadian comparison of data sources for coronary artery bypass surgery outcome 'report cards'. Am Heart J 2000, I 40(3):402-8.

9. Hannan EL, Racz MJ, Jollis JG, Peterson ED: Using Medicare claims data to assess provider quality for CABG surgery: does it work well enough? Health Serv Res 1997, 3 I (6):659-78.

10. Reid RJ, Roos NP, MacWilliam L, Forhlich N, Black C: Assessing population health care need using a claims-based ACG morbidity measure: a validation analysis in the Province of Manitoba. Health Serv Res 2002, 37(5): I345-64

II. Dominitz JA, Maynard C, Boyko EJ: Assessment of vital status in Department of Veterans Affairs national databases. comparison with state death certificates. Ann Epidemiol 2001, I I(5):286-9I.

12. Fisher SG, Weber L, Goldberg J, Davis F: Mortality ascertainment in the veteran population: alternatives to the National Death Index. Am J Epidemiol I995, I 4 I (3):242-50.

13. Page WF, Mahan CM, Kang HK: Vital status ascertainment through the files of the Department of Veterans Affairs and the Social Security Administration. Ann Epidemiol 1996, 6(2): 102-9.

14. Boyle CA, Decoufle P: National sources of vital status information: extent of coverage and possible selectivity in reporting. Am J Epidemiol 1990, I 3 I (I): I60-8.

15. Williams BC, Demitrack LB, Fries BE: The accuracy of the National Death Index when personal identifiers other than Social Security number are used. Am J Public Health 1992, 82(8): $\mid$ | $45-7$

16. Singer PA, Wolfson M: The 'best places to die': improving end of life care requires better population data. BMJ 2003, 327(7408): $\mid 73-4$.

17. Cowper DC, Hynes DM, Kubal JD, Murphy PA: Using administrative databases for outcomes research: select examples from VA Health Services Research and Development. J Med Syst 1999, 23(3):249-59.

18. Boyko EJ, Koepsell TD, Gaziano JM, Horner RD, Feussner JR: US Department of Veterans Affairs medical care system as a resource to epidemiologists. Am J Epidemiol 2000, I 5 I (3):307-I4.

19. Kubal JD, Webber S, Cowper DC, Waight S, Hynes DM: A primer on major U.S. mortality databases used in health services research. VIRec Insights; no. 5. Hines, Illinois: VA Information Resource Center 2000.
20. Death Statistical Master File Data Dictionary (2000) [http:www.dhs.cahwnet.gov/hisp/chs/OHIR/Catalog/Documentation/ Doc umentationlndex.htm.]. Accessed on August I, 2003

21. The Medical SAS Outpatient Datasets - FY2000: A VIREC Resource Guide [http://www.virec.research.med.va.gov/ RGFY2000.HTM]. Accessed on December 10, 2003

22. Szeto HC, Coleman RK, Gholami P, Hoffman BB, Goldstein MK Accuracy of computerized outpatient diagnoses in a Veterans Affairs general medicine clinic. Am J Manag Care 2002, 8:37-43.

23. Edmunds EM, Au DH, McDonell MB, Chen L, Martin DC, Teirney WM, et al:: Comparing methods to identify general internal medicine clinic patients with chronic heart failure. Am Heart J 2001, 142:1003-9.

24. Kashner MT: Agreement between administrative files and written medical records: a care of the Department of Veterans Affairs. Med Care 1998, 36(9): I324-36.

25. Refinement of the HCUP Quality Indicators Summary, Technical Review Number 4, May 2001 [http://www.ahrq.gov/clinic/epcsums/ hcupqisum.htm]. Agency for Healthcare Research and Quality, Rockville, MD

26. O'Hare AM, Dudley RA, Hynes DM, McCulloch CE, Navarro D, Colin $P$, et al.: Impact of surgeon and surgical center characteristics on choice of permanent vascular access. Kidney Int 2003, 64(2):68I-9.

27. Stockford D, Martindale ME, Pane GA: Uninsured veterans and the VHA Enrollment System. Presented at the 12th Federal Forecasters Conference. Washington, DC April 2002 [http://www.va.gov/ vhareorg/ffc/2002/Stockfordffc02.pdf]. Accessed on April I5, 2004

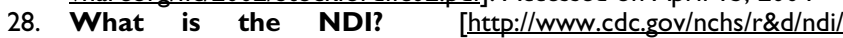
what is ndi.htm]. Accessed on November 30, 2004
Publish with Bio Med Central and every scientist can read your work free of charge

"BioMed Central will be the most significant development for disseminating the results of biomedical research in our lifetime. "

Sir Paul Nurse, Cancer Research UK

Your research papers will be:

- available free of charge to the entire biomedical community

- peer reviewed and published immediately upon acceptance

- cited in PubMed and archived on PubMed Central

- yours - you keep the copyright

Submit your manuscript here:

http://www.biomedcentral.com/info/publishing_adv.asp
BioMedcentral 